\title{
ANÁLISE DOS INDICADORES CONTÁBEIS PARA ESTIMATIVA DE RETORNO DE APLICAÇÕES: ESTUDO EMPÍRICO REALIZADO COM AS AÇÕES DAS INSTITUIÇÕES BANCARIAS LISTADAS NA BOLSA DE VALORES DE SÃO PAULO
}

\author{
Gustavo Henrique Francisco da Costa ${ }^{1}$ \\ Laércio Juarez Melz ${ }^{2}$ \\ Josiane Silva Costa dos $\operatorname{Santos}^{3}$ \\ Ariel Lopes Torres ${ }^{4}$
}

\section{RESUMO}

Com o avanço e desenvolvimento do mercado de capitais e evolução da ciência contábil, as demonstrações contábeis tornaram-se ferramentas auxiliadoras para o entendimento da situação econômico-financeira da empresa. A problemática que a pesquisa buscou investigar foi o relacionamento dos indicadores contábeis e o retorno das aplicações realizadas em ações das instituições financeiras bancárias que possuem suas ações cotadas na Bolsa de Valores de São Paulo (Bovespa). Para isso, esse trabalho utiliza o modelo de avaliação de empresa apresentado por Matarazzo (2010). Foram calculados os Índice de Estrutura de Capitais, Índices de Liquidez e Índice de Rentabilidade. Esses indicadores permitem a visão global da situação econômico-financeira da empresa. Os dados utilizados para análise, foram extraídos do banco de dados do sitio da Bovespa nos anos de 2007 a 2011. Esta pesquisa buscou colaborar para diminuir as incertezas dos investidores no mercado de ações. Não foi em todos os períodos as instituições que tiveram os melhores indicadores apresentaram melhor retorno de suas ações. O resultado dos testes empíricos para três anos, dos quatro analisados, apontou que as empresas que tiveram melhores índices no ano posterior tiveram os melhores retornos de suas ações. No entanto para um ano, 2011, os resultados obtidos apontaram para rejeição da hipótese dessa pesquisa.

Palavras-chave: Mercado de capitais. Análise de demonstrações contábeis. Instituições financeiras.

\section{INTRODUÇÃO}

As informações contábeis são de suma importância para aqueles que investem ou pretendem investir no mercado de ações, entretanto não existe uma fórmula pronta e perfeita que se possa ser empregada e venha a garantir um bom investimento (NEWLANDS JUNIOR, 2010).

Segundo Rangel (2004) os investidores vêem a análise das demonstrações financeiras como uma ferramenta capaz de prever o futuro das empresas analisadas. Tendo isso em mente esse trabalho se propôs a estudar os índices contábeis que são pertinentes a analise das

\footnotetext{
1 Acadêmico do curso de Ciências Contábeis da UNEMAT - Campus de Tangará da Serra, e-mail:gushenrique@hotmail.com

2 Mestre em Engenharia de Produção, Professor do curso de Ciências Contábeis da UNEMAT - Campus de Tangará da Serra, e-mail: laercio@unemat.br

${ }^{3}$ Contadora, Professora do curso de Ciências Contábeis da UNEMAT - Campus de Tangará da Serra.

${ }^{4}$ Mestre em Administração (UNEX), Professor do curso de Ciências Contábeis da UNEMAT - Campus de Tangará da Serra.
} 
Análise dos indicadores contábeis para estimativa de retorno de aplicações: estudo empírico realizado com as ações das instituições bancarias listadas na bolsa de valores de São Paulo

Gustavo Henrique Francisco da Costa, Laércio Juarez Melz, Josiane Silva Costa dos Santos, Ariel Lopes Torres

demonstrações contábeis, que é um mecanismo muito utilizado para avaliar o desempenho das empresas, mais específico, analisar a efetividade desses índices quando utilizados para estimar retornos das aplicações realizada no mercado de ações.

As instituições financeiras exercem um papel de extrema importância para economia do Brasil, principalmente no que se refere às intermediações financeiras. Isso porque, elas são responsáveis por viabilizar as transferências de recursos entre os agentes econômicos superavitários e deficitários do país, o que proporciona maior agilidade e segurança nas concretizações das movimentações. Essa atividade faz com que a economia brasileira seja devidamente movimentada, já que é através dos subsídios de créditos, investimentos produtivos e, da balança de pagamentos que o mercado econômico é aquecido, sendo um dos principais propulsores para o desenvolvimento do país (NEWLANDS JUNIOR, 2010).

Diante deste contexto apresentou-se a questão problema: qual a relação entre os índices contábeis e o rendimento de aplicações realizadas nas ações comercializadas, das instituições financeiras bancárias listadas na Bolsa de Valores de São Paulo (BOVESPA)? A hipótese levantada foi que, entre as instituições financeiras bancárias listadas na BOVESPA, aquelas que possuíssem os melhores índices de Estrutura de Capitais, Rentabilidade e Liquidez, apresentariam maiores retornos de suas ações.

Em consonância com a questão estabelecida, o objetivo geral da pesquisa foi investigar o relacionamento entre os índices contábeis e retorno das aplicações realizadas nas ações das instituições financeiras bancárias listadas na BOVESPA.

Os objetivos específicos foram: Identificar as instituições financeiras com ações cotadas na bolsa de valores; Calcular os índices sobre as demonstrações contábeis das entidades identificadas e Identificar se os índices possuíam relação com a cotação da bolsa de valores na estimativa de retorno dessas aplicações.

\section{FUNDAMENTAÇÃO TEÓRICA}

\subsection{Ações}

De acordo com Fortuna (2005, p. 559) "uma ação representa a menor parcela do capital social de uma sociedade por ações”. Newlands Junior (2010 p. 318) é mais preciso dizendo que "Ações são valores mobiliários, emitidos pelas companhias ou sociedades anônimas, representativos da menor parcela do capital da empresa emitente". Adicionalmente Filho e Ishikawa (2003) dizem que ações são representações do capital de uma empresa por 
Análise dos indicadores contábeis para estimativa de retorno de aplicações: estudo empírico realizado com as ações das instituições bancarias listadas na bolsa de valores de São Paulo

Gustavo Henrique Francisco da Costa, Laércio Juarez Melz, Josiane Silva Costa dos Santos, Ariel Lopes Torres

meio de títulos, tendo essas empresas a denominação de Sociedade anônima, podendo ser de capital aberto ou fechado, sendo essas regulamentadas por intermédio da lei 6.404/76. Quando a companhia é de capital aberto, está deverá ser registrada como tal perante a Comissão de Valores Mobiliários (CVM), tendo obrigações periódicas de prestar informações ao mercado a respeito do seu comportamento social, econômico e financeiro.

As ações podem ser ordinárias ou preferenciais, segue o conceito de cada uma delas de acordo com Filho e Ishikawa (2003). Ordinárias: são ações que concedem ao seu proprietário o direito ao voto nas assembleias gerais e extraordinárias, sendo que nessas assembleias que ocorrem as tomadas de decisões a respeito do destino da empresa, avaliam e votam sobre a aprovação das peças contábeis, a destinação do resultado do exercício, venda de imobilizado, aquisição de outra empresa, entre outros assuntos pertinentes

Preferênciais: são ações que não dão ao seu portador o direito ao voto, mais aqueles que são possuidores desse tipo de ação, tem preferencia no recebimento dos dividendos, e caso haja a dissolução da sociedade, estes terão prioridades no reembolso do capital.

\subsection{Mercado de Ações}

São quatro os tipos de seguimentos que constituem o setor financeiro. A termologia mercado é empregada na designação desses segmentos, os intermediários financeiros que se encontram entre os tomadores de recursos, que são aqueles que procuram ativos financeiros, e os poupadores, que são aqueles que possuem recursos sobressalentes e ofertam esses recursos, formando assim um mercado tipicamente caracterizado pela oferta e procura. Sendo eles o mercado monetário, mercado de crédito, mercado de capitais e mercado de câmbio (NEWLANDS JUNIOR 2010).

Conforme suas características o setor financeiro pode ser dividido em quatro mercado específicos, o quadro 1 mostra esses quatros mercados:

Figura 1: Segmentação dos mercados financeiros

\begin{tabular}{|c|c|c|c|}
\hline Mercado financeiro & Prazo & Objetivo & Intermediação financeira \\
\hline Mercado de crédito & $\begin{array}{l}\text { Curto, médio e } \\
\text { aleatório }\end{array}$ & $\begin{array}{c}\text { Financiamento do consumo } \\
\text { e capital de giro das } \\
\text { empresas }\end{array}$ & Bancário e não bancário \\
\hline Mercado de Capitais & $\begin{array}{l}\text { Médio, longo e } \\
\text { indeterminado }\end{array}$ & $\begin{array}{l}\text { Financiamento de capital de } \\
\text { giro, capital fixo e habitação }\end{array}$ & Não bancário \\
\hline Mercado Monetário & Curto e curtíssimo & $\begin{array}{c}\text { Controle da liquidez } \\
\text { monetária da economia e } \\
\text { suprimentos de desencaixes }\end{array}$ & Bancário e não bancário \\
\hline
\end{tabular}


Análise dos indicadores contábeis para estimativa de retorno de aplicações: estudo empírico realizado com as ações das instituições bancarias listadas na bolsa de valores de São Paulo

Gustavo Henrique Francisco da Costa, Laércio Juarez Melz, Josiane Silva Costa dos Santos, Ariel Lopes Torres

\begin{tabular}{|l|l|c|c|}
\hline Mercado Cambial & Curto e avista & $\begin{array}{c}\text { Transformação de valores } \\
\text { em moeda estrangeira em } \\
\text { nacional e vice e versa }\end{array}$ & $\begin{array}{c}\text { Bancário e auxiliares } \\
\text { (corretoras) }\end{array}$ \\
\hline
\end{tabular}

Fonte: Bruni (2005, p 19)

De acordo com as teorias de Newlands Junior (2010): Mercado Monetário, é o seguimento que esta estabelece o nível de liquidez geral da economia, é onde ocorre o controle da oferta da moeda, das taxas de juro de curto prazo, visando garantir a liquidez da economia. Sendo que o Banco central atua como regulador desse nível, como autoridade monetária.

Mercado de crédito é onde são realizadas operações de prazo curto, médio e longo, tendo como objetivo o financiar o consumo de pessoas físicas, de capital fixo e de capital de giro das sociedades. (ANDREZO, 2002)

Segundo Bruni (200) mercado de capitais é um aparelho de distribuição de valores mobiliários, tendo como objetivo proporcionar liquidez aos títulos de emissão de empresas e proporcionar seu processo de capitalização, sendo que este é composto pelas bolsa de valores, as sociedades corretoras e outras entidades financeiras autorizadas.

Mercado de câmbio é um segmento que trabalha com prazo a vista ou curto, tem como fim a mutação de moeda oriunda de outras nações em moeda nacional ou vice-versa, sendo seu intermédio e auxiliar as corretares e distribuidoras de valores e as casas de câmbio. (NEWLANDS JUNIOR, 2010)

Segundo Newlands Junior (2010), o mercado de ações está inserido no mercado de capitais que por sua vez é um dos seguimentos financeiros. Cabe a Comissão de Valores Mobiliários (CVM), uma autarquia em regime especial, a responsabilidade do desenvolvimento, regulamentação, disciplina e a fiscalização do mercado de capitais, títulos e valores mobiliários emitidos pelas Sociedades Anônimas de Capital aberto no país. Newlands Junior (2010, p. 137) define valores mobiliários como sendo "títulos emitidos pelas sociedades anônimas, que representam para aqueles que adquirem esses títulos um investimento com determinado grau de risco".

De acordo com a Comissão de Valores Mobiliários (CVM) (2012, p. 6) o mercado de capitais é "um conjunto de mercados, instituições e ativos que viabiliza a transferência de recursos financeiros entre tomadores (companhia abertas) e aplicadores (investidores) destes recursos." Sendo que essa transferência se dá por intermédio de operações financeiras, 
Análise dos indicadores contábeis para estimativa de retorno de aplicações: estudo empírico realizado com as ações das instituições bancarias listadas na bolsa de valores de São Paulo

Gustavo Henrique Francisco da Costa, Laércio Juarez Melz, Josiane Silva Costa dos Santos, Ariel Lopes Torres

podendo ocorrer de forma direta entre o investidor e a companhia ou por meio de intermediários financeiros.

Segundo Fortuna (2005) pode se dizer que o mercado de ações é dividido em duas partes: o mercado primário, e mercado secundário. Sendo que o mercado primário se dá quando as ações de uma sociedade são emitidas abertamente ao público, por intermédio de uma oferta pública, a CVM (2012) é mais clara na definição de mercado primário, dizendo que esse mercado ocorre quando do primeiro lançamento das ações no mercado, e os recursos obtidos a partir das vendas desses títulos são direcionados para as sociedades que a eles deram origem.

Figura 2 Mercado de Capitais Primário

\section{MERCADO DE CAPITAIS MERCADO PRIMÁRIO}

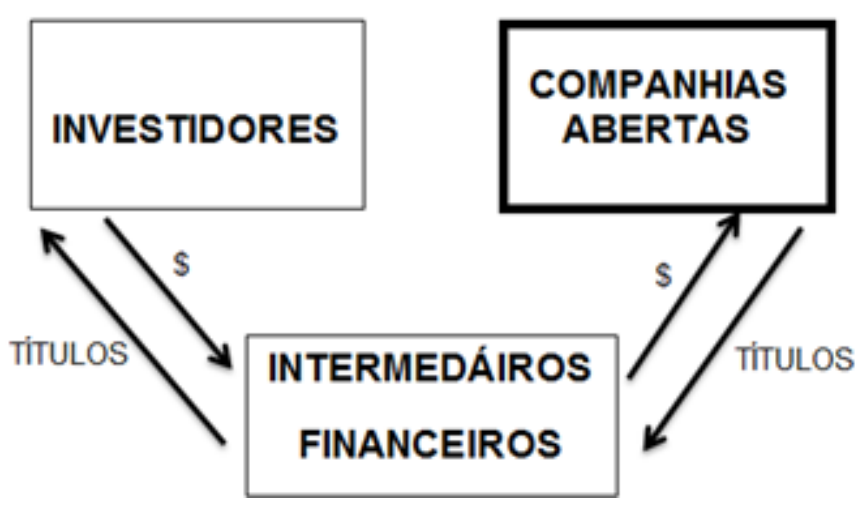

Fonte: CVM (2012, p.8)

Fortuna (2005) relata que o mercado secundário, é local onde as ações que já foram emitidas pelas sociedades são comercializadas através das bolsas de valores. A CVM (2012) é precisa conceituando o mercado secundário como sendo o local onde os investidores, que compraram essas ações anteriormente no mercado primário, comercializam essas ações, sendo que essa comercialização pode ser feita de forma direta, onde um investidor vende para outro investidor, ou pode ser realizada por intermédio de uma instituição, sendo que essas têm como objetivo, proporcionar aos investidores a comercializações dessas ações de maneira eficiente e segura, sendo exemplos dessas instituições a bolsa de valores e o mercado de balcão organizado. 
Análise dos indicadores contábeis para estimativa de retorno de aplicações: estudo empírico realizado com as ações das instituições bancarias listadas na bolsa de valores de São Paulo

Gustavo Henrique Francisco da Costa, Laércio Juarez Melz, Josiane Silva Costa dos Santos, Ariel Lopes Torres

Figura 3 Mercado de Capitais Secundário

\section{MERCADO DE CAPITAIS}

MERCADO SECUNDÁRIO

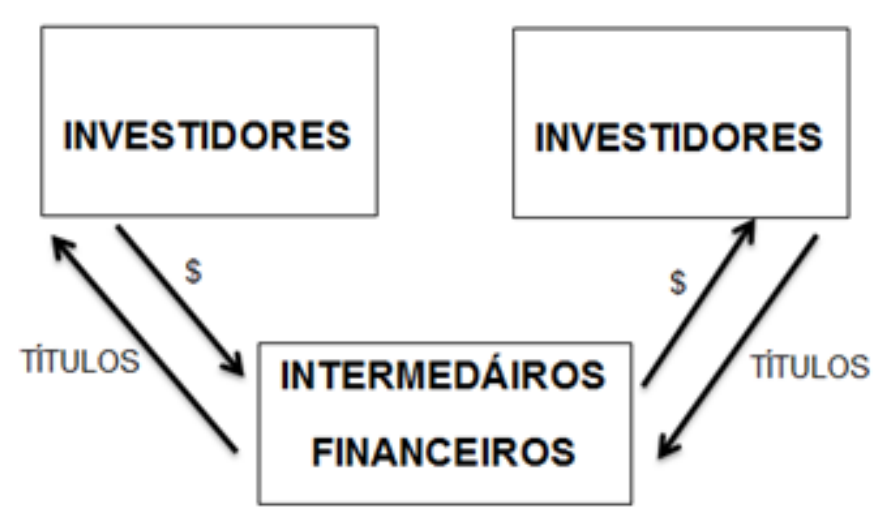

Fonte: CVM (2012. p. 10)

Bolsa de valores são associações que podem ser na forma de civis que não possuem fins lucrativos ou na forma de Sociedade Anônima, estas visando lucratividade, são utilizadas pra fornecer infraestrutura para o mercado de ações, e são formadas pelas corretoras de valores, é o local criado e mantido para as negociações de ações debentures e outros, em mercado livre e aberto, no Brasil há somente a Bolsa de Valores de São Paulo (Bovespa). (FORTUNA 2005)

Newlands Junior (2010) relata que a Bovespa, que surgiu em 1985, era uma sociedade civil sem fins lucrativos, mas, no ano de 2007, ela abre seu capital transformando-se em uma Sociedade Anônima de capital aberto. no ano de 2008 a Bovespa fundiu-se com a Bolsa de Mercadorias e Futuros (BM\&F), nascendo assim uma nova instituição intitulada de BM\&FBOVESPA.

Quando as ações são comercializadas fora da bolsa de valores, dizemos então que essas estão sendo compradas e vendidas por intermédio de um mercado de balcão, sendo que esse ambiente divide-se em dois, mercado de balcão organizado e mercado de balcão não organizado. De acordo com a CVM (2012, p.11) o mercado de balcão organizado é "um ambiente administrado por instituições auto reguladoras que propiciam sistemas informatizados e regras para a negociação de títulos e valores mobiliários. Estas instituições são autorizadas a funcionar pela CVM e por ela são supervisionadas”.

O mercado de balcão não organizado, é onde ocorre a comercialização das ações sem que haja um local físico para isso, e não é coordenado por uma instituição auto reguladora, dessa forma nota-se que a principal diferença entre o mercado de balcão organizado e o 
Análise dos indicadores contábeis para estimativa de retorno de aplicações: estudo empírico realizado com as ações das instituições bancarias listadas na bolsa de valores de São Paulo

Gustavo Henrique Francisco da Costa, Laércio Juarez Melz, Josiane Silva Costa dos Santos, Ariel Lopes Torres

mercado de balcão não organizado, é o fato do primeiro se constituir por intermédio de uma instituição auto reguladora, e outro não, observa-se também que o segundo não possui um sistema de informação integrado.

\subsection{Análise das Demonstrações Contábeis}

Ribeiro (2002, p. 16) conceitua Análise de Balanço como sendo "uma arte por meio da qual são analisadas e interpretadas as principais demonstrações financeiras de uma entidade, visando fornecer informações a cerca do estado do seu patrimônio". "A Análise de Balanços é uma técnica contábil que consiste no exame e na interpretação dos dados contidos nas demonstrações contábeis, com o fim de transformar esses dados em informações uteis aos diversos usuários da contabilidade" (RIBEIRO 2009, p.7)

De acordo com Marion (2007) as analise das Demonstrações Contábeis é algo antigo quanto à própria Contabilidade, mas é no final do século XIX que surgi com mais solidez, onde os banqueiros americanos solicitavam as demonstrações das empresas que almejavam conseguir empréstimos, como primeiramente existia somente o Balanço para a Análise é da onde que surgi o termo Análise de Balanços, que persiste até os dias atuais.

Segundo Matarazzo (2007, p. 15) “A Análise de Balanços objetiva extrair informações das Demonstrações Financeiras para a tomada de decisões.” Matarazzo (2007, p. 15) diz ainda

As demonstrações financeiras fornecem uma série de dados sobre a empresa, de acordo com regras contábeis. A Análise de Balanços transforma esses dados em informações e será tanto mais eficiente quanto melhores informações produzir.

A Análise de Balanço tem como finalidade transformar os dados que são extraídos das demonstrações financeiras em informações que sirvam como subsídios para tomada de decisões dos interessados. (RIBEIRO, 2002).

Segundo Marion (2007, p. 24) “Os indicadores (ou índices ou quocientes) significam o resultado obtido da divisão de duas grandezas”. Matarazzo (2007) é mais claro, dizendo que os índices são a analogia entre grupos de contas das Demonstrações financeiras, que tem como finalidade fornecer uma ótica ampliada da situação financeira e econômica da empresa.

Entende-se que, antes de aplicar seus recursos em uma determinada empresa, o investidor procura se informar a respeito da situação econômica e financeira da empresa em questão, pois tendo uma visão de lucro, não teria sentido o investidor aplicar seus recursos em uma instituição que não esteja bem econômica e financeiramente, diante do exposto Ribeiro (2009) diz que a análise por quociente é a mais comumente empregada para se ter 
Análise dos indicadores contábeis para estimativa de retorno de aplicações: estudo empírico realizado com as ações das instituições bancarias listadas na bolsa de valores de São Paulo

Gustavo Henrique Francisco da Costa, Laércio Juarez Melz, Josiane Silva Costa dos Santos, Ariel Lopes Torres

uma ótica globalizada a respeito da situação econômica e financeira da empresa. Para Ribeiro (2009) os quocientes de Estrutura de capitais, liquidez e Rentabilidade, são suficientes para alcançar um diagnóstico sucinto a cerca da situação econômica e financeira de qualquer tipo de empresa.

Estrutura de Capitais: de acordo com Ribeiro (2009) os índices de estrutura de capitais são empregados para demonstrar o grau de endividamento da instituição em virtude das origens dos capitais investidos no patrimônio. Eles evidenciam a proporção existente entre o capital próprio e o capital de terceiros, sendo que esses índices são obtidos a partir de dados extraídos do Balanço patrimonial da empresa que está sendo analisada.

Liquidez: os índices de liquidez também chamados de índice de solvência, evidenciam o grau de solvência da situação financeira da entidade em relação a sua capacidade de pagamento de compromissos assumidos com terceiros. Estes índices demonstram a proporção que existe entre os investimento investimentos que foram realizados no ativo circulante e os capitais de terceiros (passivo circulante), esses índices são obtidos a partir de cálculos de valores extraídos do Balanço Patrimonial.( RIBEIRO, 2009)

Rentabilidade: segundo Ribeiro (2009) esses índices servem para medir a capacidade econômica da empresa, ou seja, ele demonstra o grau do resultado econômico obtido pelo capital que foi investido na empresa. Esses índices são calculados a partir do confronto dos grupos de contas da Demonstração do Resultado do Exercício e do Balanço Patrimonial da empresa que está sendo analisada.

Para desenvolvimento dessa pesquisa, será considerado os índices anteriormente referenciados, sendo eles Estrutura de Capitais, Liquidez e Rentabilidade, conforme sugeridos por Ribeiro (2009), que são o suficiente para se obter um diagnóstico sucinto a respeito da situação economia e financeira de qualquer empresa. Segue as fórmulas dos respectivos índices que serão adotados nessa pesquisa.

Quadro 1 Resumo dos Quocientes

\begin{tabular}{|c|c|c|}
\hline \multirow{2}{*}{ Estrutura de Capitais } & 1. Participação de Capitais de Terceiros & FÓRMULA \\
\cline { 2 - 3 } & 2. Composição do Endividamento & Exigível Total \\
& Patrimônio Líquido \\
\hline
\end{tabular}


Análise dos indicadores contábeis para estimativa de retorno de aplicações: estudo empírico realizado com as ações das instituições bancarias listadas na bolsa de valores de São Paulo

Gustavo Henrique Francisco da Costa, Laércio Juarez Melz, Josiane Silva Costa dos Santos, Ariel Lopes Torres

\begin{tabular}{|c|c|c|}
\hline & 3. Imobilização do Patrimônio Líquido & $\begin{array}{l}\text { Ativo Não-Circulante - } \\
\text { Realizável a Longo Prazo } \\
\text { Patrimônio Líquido }\end{array}$ \\
\hline & $\begin{array}{l}\text { 4. Imobilização dos Recursos Não } \\
\text { Correntes }\end{array}$ & 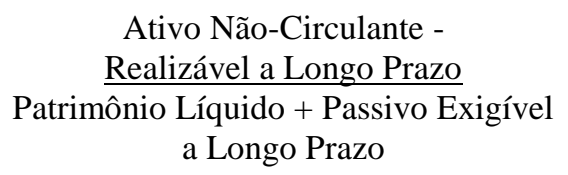 \\
\hline \multirow{4}{*}{ Liquidez ou Solvência } & 5. Liquidez Geral & $\begin{array}{c}\text { Ativo Circulante }+ \\
\frac{\text { Ativo Realizável a Longo Prazo }}{\text { Passivo Circulante + Passivo Exigível a }} \\
\begin{array}{c}\text { longo Prazo } \\
\text { Pival }\end{array}\end{array}$ \\
\hline & 6. Liquidez Corrente & $\frac{\text { Ativo Circulante }}{\text { Passivo Circulante }}$ \\
\hline & 7. Liquidez Seca & $\frac{\text { Ativo Circulante - Estoques }}{\text { Passivo Circulante }}$ \\
\hline & 8. Giro do Ativo & $\frac{\text { Vendas Líquidas }}{\text { Ativo Total }}$ \\
\hline \multirow{3}{*}{ Rentabilidade } & 9. Margem Líquida & $\frac{\text { Lucro Líquido }}{\text { Vendas Líquidas }}$ \\
\hline & 10. Rentabilidade do Ativo & $\frac{\text { Lucro Líquido }}{\text { Ativo Total }}$ \\
\hline & 11. Rentabilidade do Patrimônio Líquido & $\frac{\text { Lucro Líquido }}{\text { Patrimônio Líquido }}$ \\
\hline
\end{tabular}

Fonte: Adaptado de Ribeiro (2008, p. 174)

\title{
2.4 Instituições financeiras Bancárias
}

De acordo com a Lei no 7.492/86 (2002 apud Andrezo e Lima) instituições financeiras são

\begin{abstract}
as pessoas jurídicas públicas ou privadas que tem como atividade principal ou acessória a coleta, intermediação ou aplicação de recursos financeiros próprios ou de terceiros, em moeda nacional ou estrangeira, e a custódia de valor de propriedade de terceiros. Além disso, equipara ás instituições financeiras as pessoas físicas que realizam qualquer dessas atividades de forma permanente e eventual,
\end{abstract}

Andrezo e Lima (2002, p. 50) complementa sua conceituação sobre as instituições financeiras, dizendo que os "estabelecimentos bancários oficiais ou privados, as sociedades de crédito, financiamento e investimento, as caixas econômicas e as cooperativas de crédito, são consideradas instituições financeiras."

Segundo Fortuna (2005), o modelo bancário que foi inserido no Brasil, na época do Brasil Império, é o modelo europeu, nesta época os bancos realizavam apenas atividades de depósito e empréstimo, outros tipos de prestação de serviços não existiam. Conforme Costa 
Análise dos indicadores contábeis para estimativa de retorno de aplicações: estudo empírico realizado com as ações das instituições bancarias listadas na bolsa de valores de São Paulo

Gustavo Henrique Francisco da Costa, Laércio Juarez Melz, Josiane Silva Costa dos Santos, Ariel Lopes Torres

Neto (2004) em 1808 foi criado o primeiro banco no Brasil sendo este nominado de Banco do Brasil, que teve sua criação dada a partir de um Ato Real de D. João VI.

Nos dias atuais os bancos aumentaram numericamente, tomando como ramo varias atividades difundidas, havendo assim a necessidade separa-los por atividades, conforme Mellagi e Ishikawa ( 2003) os bancos são divididos de acordo com sua operacionalidade, sendo bancos comerciais, caixas econômicas, bancos de desenvolvimento, bancos cooperativos, bancos de investimento e bancos múltiplos.

De acordo com o Banco Central do Brasil (BCB, 2012) os bancos comerciais são instituições financeiras de públicas ou privadas, cuja a finalidade é "proporcionar suplemento de recursos necessários para financiar, a curto e médio prazos, o comércio, a indústria, as empresas prestadores de serviços, as pessoas físicas e a terceiros em geral." Tem como atividade típica a captação de depósitos a vista. Sua constituição deve se dar na forma de sociedade anônima, devendo constar em sua razão social a expressão "banco" (CMN, 1994).

Conforme Mellagi e Ishikawa (2003) as caixas econômicas são semelhantes aos bancos comerciais, observado que podem receber depósitos avista em caderneta de poupança, são instituições que atuam na concessão de empréstimos e financiamentos a programas e projetos na área social, habitacional, educação, saúde, transportes urbanos, esportes e trabalho.

Os bancos de desenvolvimento são instituições financeiras cujo seu controle cabe aos governos estaduais, fazendo uso de verbas públicas visando "proporcionar o suprimento oportuno e adequado dos recursos necessários ao financiamento, a médio e a longos prazos, de programas de projetos que visem a promover o desenvolvimento econômico e social dos respectivos estados." (BCB 2012). Sua constituição deve se dar na forma de sociedade anônima, sendo sua sede na capital do Estado, devendo constar em sua razão social a expressão "Banco de Desenvolvimento" acrescida do nome do Estado, conforme resolução CMN 34, de 1976.

Os bancos cooperativos são bancos comerciais com natureza de sociedade anônima de capital fechado, com participações exclusivas de cooperativas de crédito singulares que atuam restritamente em sua unidade de federação, cujas criações são autorizadas por meio da Resolução 2.193 de 1995. (FILHO E ISHIKAWA 2003)

Segundo o BCB (2012) os bancos de investimento "são instituições financeiras privadas especializadas em operações de participação societária de caráter temporário, de 
Análise dos indicadores contábeis para estimativa de retorno de aplicações: estudo empírico realizado com as ações das instituições bancarias listadas na bolsa de valores de São Paulo

Gustavo Henrique Francisco da Costa, Laércio Juarez Melz, Josiane Silva Costa dos Santos, Ariel Lopes Torres

financiamento da atividade produtiva para suprimento de capital fixo e de giro e de administração de recursos de terceiros.” Sua constituição deve se dar na forma de sociedade anônima, devendo constar em sua razão social a expressão "Banco de Investimento" conforme resolução CMN 2.624 de 1999.

Os bancos múltiplos, são instituições financeiras privadas ou públicas que opera com pelo menos duas carteiras, que de acordo com BCB (2012) sendo uma dessas obrigatoriamente comerciais ou de investimento, "visando realizar as operações ativas, passivas e acessórias das diversas instituições financeiras". Sua constituição deve se dar na forma de sociedade anônima, devendo constar em sua razão social a expressão "banco", conforme a resolução CMN 2.099, de 1994.

\section{METODOLOGIA}

Conforme Oliveira (2002) a abordagem dessa pesquisa é dada de forma quantitativa, pois procura quantificar dados, na forma de coleta de informações, empregando ferramentas estáticas.

A partir dos suportes técnicos utilizados nessa pesquisa de acordo com Severino (2007), esta pesquisa pode ser reconhecido como histórico-bibliográfico e documental, pelo fato de ser composta decorrente de pesquisas anteriores, documentos impressos, artigos, livros, teses, não somente fazendo uso desses documentos impressos, mas também outros tipos de documentos legais como sítios de autoria governamental.

De acordo com objeto de estudo dessa pesquisa ela pode ser classificada como explicativa, pois busca além de registrar e analisar os fenômenos procura identificar suas causas (ligação entre os rendimentos das ações e os indicadores contábeis)(SEVERINO, 2007).

As ações das empresas analisadas serão do tipo preferencial, que de acordo com Mellagi e Ishikawa (2003), possuem maior liquidez. Instituições financeiras bancárias a serem analisadas são ao todo 28 (vinte e oito) de acordo com o sitio da BOVESPA.

Os índices que serão calculados são os de Liquidez, Estrutura de Capital e Rentabilidade, apontados por Matarazzo (2003) e Ribeiro (2009). As demonstrações serão analisadas com periodicidade anual, durante um período de 5 (cinco) anos sendo de 2007 a 2011, e o período das cotações que serão utilizados, serão de forma anual para ter um relacionamento direto com o período que serão realizada as análise das demonstrações. 
Análise dos indicadores contábeis para estimativa de retorno de aplicações: estudo empírico realizado com as ações das instituições bancarias listadas na bolsa de valores de São Paulo

Gustavo Henrique Francisco da Costa, Laércio Juarez Melz, Josiane Silva Costa dos Santos, Ariel Lopes Torres

As Demonstrações Contábeis utilizadas para análise, foram extraídas do banco de dados do sitio da Bovespa, sendo necessário para sua visualização a utilização dos softwares Sistema de Divulgação Externa ITR/DFP/IAN 9.2.0 e EmpresasNet, ambos disponíveis para download no sitio da Bovespa.

Foram selecionados os dados de 28 (vinte e oito) instituições financeiras que possuem suas ações cotadas na Bovespa, para os anos de 2007 a 2011. Atendendo assim ao primeiro objetivo especifico. Porém, dessas não foram utilizadas as que não possuíam dados contábeis nesse período, e as que não possuíam ações do tipo preferenciais. No total foram descartadas 08 (oito) instituições financeiras, constituindo uma amostra para a pesquisa de 20 (vinte) instituições.

Foi realizada padronização dos dados coletados, agrupando-os em grupos limitados a serem utilizados nos cálculos dos índices. De acordo com Matarazzo (2003 p. 145) "este trabalho é chamado de Padronização e consiste numa critica ás contas das demonstrações financeiras, bem como na transcrição delas para um modelo previamente definido".

Depois da padronização e agrupamento dos dados, foram calculados os índices:

1. Estrutura de capital: Participação de Capitais de Terceiros (ET/PL), Composição do Endividamento (PC/ET), Imobilização do Patrimônio Líquido (ANC-RLP/PL) e Imobilização de Recursos não Correntes (ANCRLP/PL+PELP);

2. Liquidez: Liquidez Geral (AC+RLP/PC+PELP), Liquidez Corrente (AC/PC) e Liquidez Seca (AC-E/PC);

3. Rentabilidade: Giro do Ativo (VL/AT), Margem Líquida (LL/VL), Rentabilidade do Ativo (LL/AT) e Rentabilidade do Patrimônio Líquido (LL/PL)

\section{RESULTADOS}

Devido ao fato dessa pesquisa se apresentar em forma de um artigo cientifico, tendo restrições a quantidades de laudas, foram apresentados os resultados das etapas do tratamento dos dados somente para ao ano de 2009, sendo esse escolhido por ser o ano meio dos anos que esta pesquisa se propôs a analisar, mas o resultado final foi apresentado para todos os anos que abrangem essa pesquisa, para que os interessados possam ter uma melhor visão de como se comportaram os indicadores e os retornos das ações. Dessa forma consentindo com 
Análise dos indicadores contábeis para estimativa de retorno de aplicações: estudo empírico realizado com as ações das instituições bancarias listadas na bolsa de valores de São Paulo

Gustavo Henrique Francisco da Costa, Laércio Juarez Melz, Josiane Silva Costa dos Santos, Ariel Lopes Torres

o segundo objetivo secundário dessa pesquisa, foram calculados os indicadores contábeis para todas 20 (vinte) instituições financeiras bancárias conforme demonstra a tabela1. 
Análise dos indicadores contábeis para estimativa de retorno de aplicações: estudo empírico realizado com as ações das instituições bancarias listadas na bolsa de valores de São Paulo

Gustavo Henrique Francisco da Costa, Laércio Juarez Melz, Josiane Silva Costa dos Santos, Ariel Lopes Torres

\begin{tabular}{|c|c|c|c|c|c|c|c|c|c|c|c|}
\hline \multirow[b]{2}{*}{ Empresas } & \multicolumn{4}{|c|}{ Estrutura de Capitais } & \multicolumn{3}{|c|}{ Liquidez } & \multicolumn{4}{|c|}{ Rentabilidade } \\
\hline & $\mathrm{ET} / \mathrm{PL}$ & $\begin{array}{c}\mathrm{PC} / \mathrm{E} \\
\mathrm{T}\end{array}$ & $\begin{array}{l}\text { ANC- } \\
\text { RLP/PL }\end{array}$ & $\begin{array}{c}\text { ANC- } \\
\text { RLP/PL+PEL } \\
\text { P }\end{array}$ & LG & $\mathrm{LC}$ & LS & $\begin{array}{l}\mathrm{VL} / \mathrm{A} \\
\mathrm{T}\end{array}$ & $\mathrm{LL} / \mathrm{VL}$ & $\begin{array}{l}\mathrm{LL} / \mathrm{A} \\
\mathrm{T}\end{array}$ & $\begin{array}{c}\mathrm{LL} / \mathrm{P} \\
\mathrm{L}\end{array}$ \\
\hline ALFA HOLDINGS S.A & 1,71 & $\begin{array}{c}100,0 \\
0\end{array}$ & 98,37 & 98,37 & $\begin{array}{c}1,9 \\
5\end{array}$ & $\begin{array}{c}1,8 \\
7\end{array}$ & $\begin{array}{c}1,8 \\
7\end{array}$ & 0,00 & $\begin{array}{c}35.525,1 \\
7\end{array}$ & 10,55 & 10,73 \\
\hline $\begin{array}{l}\text { BANESTES S.A. - BCO EST ESPIRITO } \\
\text { SANTO }\end{array}$ & $\begin{array}{l}1.390,2 \\
3\end{array}$ & 81,22 & 22,22 & 6,15 & $\begin{array}{c}1,0 \\
6\end{array}$ & $\begin{array}{c}0,8 \\
5\end{array}$ & $\begin{array}{c}0,8 \\
5\end{array}$ & 0,04 & 36,25 & 1,57 & 23,35 \\
\hline BCO ABC BRASIL S.A & 503,87 & 74,15 & 3,85 & 1,67 & $\begin{array}{c}1,1 \\
9\end{array}$ & $\begin{array}{c}1,1 \\
5\end{array}$ & $\begin{array}{c}1,1 \\
5\end{array}$ & 0,05 & 42,60 & 2,05 & 12,41 \\
\hline BCO ALFA DE INVESTIMENTO S.A & 918,07 & 71,82 & 58,10 & 16,20 & $\begin{array}{c}1,0 \\
5\end{array}$ & $\begin{array}{c}0,7 \\
0\end{array}$ & $\begin{array}{c}0,7 \\
0\end{array}$ & 0,01 & 68,59 & 0,77 & 7,83 \\
\hline BCO BRADESCO S.A & $\begin{array}{l}1.122,4 \\
0\end{array}$ & 60,50 & 198,60 & 36,55 & $\begin{array}{c}0,9 \\
1\end{array}$ & $\begin{array}{c}1,1 \\
4\end{array}$ & $\begin{array}{c}1,1 \\
4\end{array}$ & 0,03 & 57,72 & 1,57 & 19,19 \\
\hline BCO CRUZEIRO DO SUL S.A & 572,55 & 63,80 & 19,12 & 6,22 & $\begin{array}{c}1,1 \\
4\end{array}$ & $\begin{array}{c}1,4 \\
8\end{array}$ & $\begin{array}{c}1,4 \\
8\end{array}$ & 0,07 & 15,61 & 1,14 & 7,66 \\
\hline BCO DAYCOVAL S.A & 309,88 & 63,18 & 3,81 & 1,78 & $\begin{array}{c}1,3 \\
1\end{array}$ & $\begin{array}{c}1,4 \\
9\end{array}$ & $\begin{array}{c}1,4 \\
9\end{array}$ & 0,02 & 125,19 & 3,04 & 12,47 \\
\hline BCO ESTADO DE SERGIPE S.A. - BANESE & $\begin{array}{c}1.406,5 \\
6\end{array}$ & 64,37 & 34,74 & 5,78 & $\begin{array}{c}1,0 \\
5\end{array}$ & $\begin{array}{c}1,0 \\
1\end{array}$ & $\begin{array}{c}1,0 \\
1\end{array}$ & 0,08 & 23,01 & 1,75 & 26,33 \\
\hline $\begin{array}{c}\text { BCO ESTADO DO RIO GRANDE DO SUL } \\
\text { S.A }\end{array}$ & 759,14 & 82,78 & 18,93 & 8,21 & $\begin{array}{c}1,1 \\
1\end{array}$ & $\begin{array}{c}0,8 \\
1\end{array}$ & $\begin{array}{c}0,8 \\
1\end{array}$ & 0,07 & 25,83 & 1,85 & 15,88 \\
\hline BCO INDUSTRIAL E COMERCIAL S.A & 528,61 & 75,69 & 12,75 & 5,58 & $\begin{array}{c}1,1 \\
7\end{array}$ & $\begin{array}{c}1,1 \\
6\end{array}$ & $\begin{array}{c}1,1 \\
6\end{array}$ & 0,07 & 42,70 & 2,88 & 18,11 \\
\hline BCO INDUSVAL S.A & 530,44 & 71,45 & 5,46 & 2,17 & $\begin{array}{c}1,1 \\
8\end{array}$ & $\begin{array}{c}1,3 \\
6\end{array}$ & $\begin{array}{c}1,3 \\
6\end{array}$ & 0,03 & 14,49 & 0,47 & 2,95 \\
\hline $\begin{array}{l}\text { BCO MERCANTIL DE INVESTIMENTOS } \\
\text { S.A }\end{array}$ & $\begin{array}{c}3.774,9 \\
8\end{array}$ & 9,24 & 0,04 & 0,00 & $\begin{array}{c}1,0 \\
3\end{array}$ & $\begin{array}{c}2,0 \\
3\end{array}$ & $\begin{array}{c}2,0 \\
3\end{array}$ & 0,01 & 35,24 & 0,23 & 8,97 \\
\hline BCO MERCANTIL DO BRASIL S.A & $\begin{array}{c}1.312,6 \\
4\end{array}$ & 53,39 & 52,48 & 7,37 & $\begin{array}{c}1,0 \\
4\end{array}$ & $\begin{array}{c}1,3 \\
9\end{array}$ & $\begin{array}{c}1,3 \\
9\end{array}$ & 0,09 & 5,96 & 0,52 & 7,40 \\
\hline BCO NORDESTE DO BRASIL S.A & 824,12 & 47,48 & 9,48 & 1,78 & $\begin{array}{c}1,1 \\
1\end{array}$ & $\begin{array}{c}1,3 \\
7\end{array}$ & $\begin{array}{c}1,3 \\
7\end{array}$ & 0,04 & 58,42 & 2,40 & 22,15 \\
\hline BCO PANAMERICANO S.A & 472,41 & 57,04 & 17,48 & 5,77 & $\begin{array}{c}1,1 \\
7\end{array}$ & $\begin{array}{c}1,0 \\
8\end{array}$ & $\begin{array}{c}1,0 \\
8\end{array}$ & 0,16 & 12,13 & 1,90 & 10,89 \\
\hline
\end{tabular}

Tabela 1 lista de Índices das Instituições Financeiras Bancárias no de 2009 
Análise dos indicadores contábeis para estimativa de retorno de aplicações: estudo empírico realizado com as ações das instituições bancarias listadas na bolsa de valores de São Paulo

Gustavo Henrique Francisco da Costa, Laércio Juarez Melz, Josiane Silva Costa dos Santos, Ariel Lopes Torres

\begin{tabular}{|c|c|c|c|c|c|c|c|c|c|c|c|}
\hline BCO PINE S.A & 747,53 & 74,39 & 4,76 & 1,63 & $\begin{array}{c}1,1 \\
3\end{array}$ & $\begin{array}{c}1,1 \\
4\end{array}$ & $\begin{array}{c}1,1 \\
4\end{array}$ & 0,00 & $2.290,14$ & 1,24 & 10,53 \\
\hline BCO SANTANDER (BRASIL) S.A & 445,75 & 62,16 & 71,89 & 26,76 & $\begin{array}{c}1,0 \\
6\end{array}$ & $\begin{array}{c}0,9 \\
8\end{array}$ & $\begin{array}{c}0,9 \\
8\end{array}$ & 0,03 & 18,16 & 0,51 & 2,79 \\
\hline BCO SOFISA S.A & 532,10 & 53,41 & 57,56 & 16,54 & $\begin{array}{c}1,0 \\
8\end{array}$ & $\begin{array}{c}1,2 \\
7\end{array}$ & $\begin{array}{c}1,2 \\
7\end{array}$ & 0,04 & 6,21 & 0,22 & 1,39 \\
\hline BRB BCO DE BRASILIA S.A & 990,33 & 80,99 & 34,46 & 11,96 & $\begin{array}{c}1,0 \\
7\end{array}$ & $\begin{array}{c}0,7 \\
6\end{array}$ & $\begin{array}{c}0,7 \\
6\end{array}$ & 0,11 & 27,90 & 3,00 & 32,76 \\
\hline $\begin{array}{c}\text { CONSORCIO ALFA DE ADMINISTRACAO } \\
\text { S.A }\end{array}$ & 0,99 & $\begin{array}{c}100,0 \\
0\end{array}$ & 98,79 & 98,79 & $\begin{array}{c}2,2 \\
2\end{array}$ & $\begin{array}{c}2,1 \\
3\end{array}$ & $\begin{array}{c}2,1 \\
3\end{array}$ & 0,00 & $8.267,14$ & 7,18 & 7,26 \\
\hline
\end{tabular}

Depois de calculados os índices contábeis apontados por Matarazzo (2003) e Ribeiro (2009). Para análise e tratamento dos índices foram utilizadas ferramentas estatísticas como a mediana, que possibilitou conhecer e definir a posição relativa de cada dado em sua ordem de grandeza (SILVA et al, 2006). O percentil foi empregado, por apresentar uma visão abrangente dos índices tabulados, de acordo com Silva (et al, 2006) os percentis são múltiplos dos decis, dessa forma foi utilizado a mesma metodologia empregada por Matarazzo (2010). A média foi utilizada para visualizar os retorno das ações por grupo de instituições.

A tabela 2 mostra os índices padrões anuais das instituições financeiras listadas na Bolsa de Valores de São Paulo.

Tabela 2 Índices-padrão das Instituições Financeiras no de 2008

\begin{tabular}{|c|c|c|c|c|c|c|c|c|c|c|}
\hline & Índices / Decil & $1^{\circ}$ Decil & $2^{\circ}$ Decil & $3^{\circ}$ Decil & $4^{\circ}$ Decil & $5^{\circ}$ Decil & $6^{\circ}$ Decil & $7^{\circ}$ Decil & $8^{\circ}$ Decil & $9^{\circ}$ Decil \\
\hline$\pi \cdot \frac{\Omega}{2}$ & ET/PL & 279,07 & 467,08 & 521,19 & 531,43 & 660,04 & 785,13 & 939,75 & $1.160,45$ & $1.391,86$ \\
\hline 菶: & $\mathrm{PC} / \mathrm{ET}$ & 52,80 & 56,31 & 61,66 & 63,55 & 67,91 & 72,75 & 74,78 & 81,04 & 84,50 \\
\hline E & ANC-RLP/PL & 3,85 & 5,32 & 11,77 & 18,35 & 20,67 & 34,57 & 54,00 & 60,86 & 98,41 \\
\hline 포 욜 & ANC-RLP/PL+PELP & 1,67 & 1,78 & 4,56 & 5,77 & 6,19 & 7,71 & 13,23 & 18,59 & 42,73 \\
\hline$\frac{8}{N}$ & LG & 1,04 & 1,05 & 1,06 & 1,07 & 1,11 & 1,13 & 1,17 & 1,18 & 1,38 \\
\hline 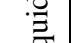 & $\mathrm{LC}$ & 0,81 & 0,96 & 1,06 & 1,14 & 1,15 & 1,31 & 1,37 & 1,48 & 1,88 \\
\hline$\stackrel{5}{3}$ & LS & 0,81 & 0,96 & 1,06 & 1,14 & 1,15 & 1,31 & 1,37 & 1,48 & 1,88 \\
\hline$\frac{\pi}{0}$ & VL/AT & 0,00 & 0,01 & 0,03 & 0,03 & 0,04 & 0,05 & 0,07 & 0,07 & 0,09 \\
\hline : 20 & LL/VL & 11,54 & 15,39 & 21,55 & 27,07 & 35,75 & 42,64 & 57,93 & 79,91 & $2.887,84$ \\
\hline 吾 & LL/AT & 0,44 & 0,52 & 1,03 & 1,44 & 1,66 & 1,87 & 2,15 & 2,90 & 3,45 \\
\hline$\underline{\underline{\underline{E}}}$ & LL/PL & 2,94 & 7,37 & 7,78 & 9,91 & 10,81 & 12,43 & 16,55 & 19,78 & 23,65 \\
\hline
\end{tabular}

Foi utilizada a mesma doutrina de conceitos apontados por Matarazzo (2010). Interpretou-se que os índices de Estrutura de Capitais quanto menor melhor, o os Índices de liquidez e Rentabilidade quanto maior melhor, como demonstra a figura 4. 
Análise dos indicadores contábeis para estimativa de retorno de aplicações: estudo empírico realizado com as ações das instituições bancarias listadas na bolsa de valores de São Paulo

Gustavo Henrique Francisco da Costa, Laércio Juarez Melz, Josiane Silva Costa dos Santos, Ariel Lopes Torres

Figura 4 Conceitos Atribuídos aos Índices de acordo com a sua posição relativa. fudices do tipo quanto menor, melhor

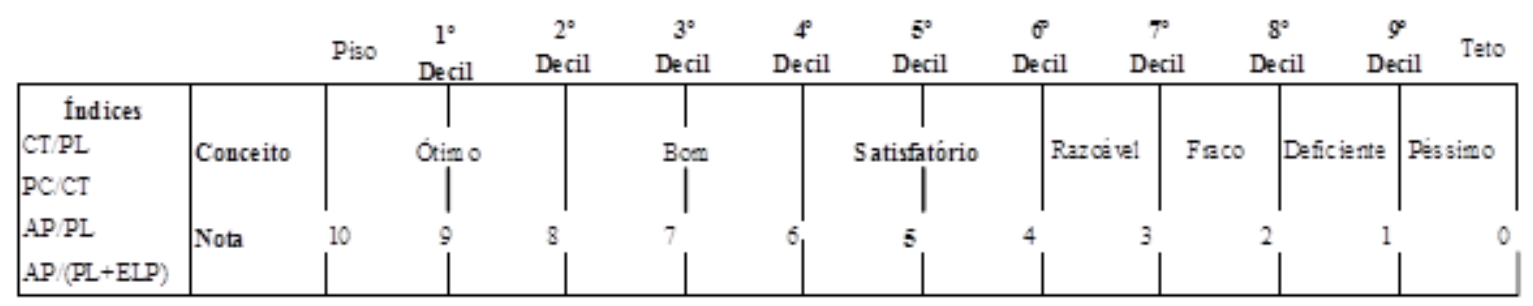

fndices do tip o quanto maior, melhor

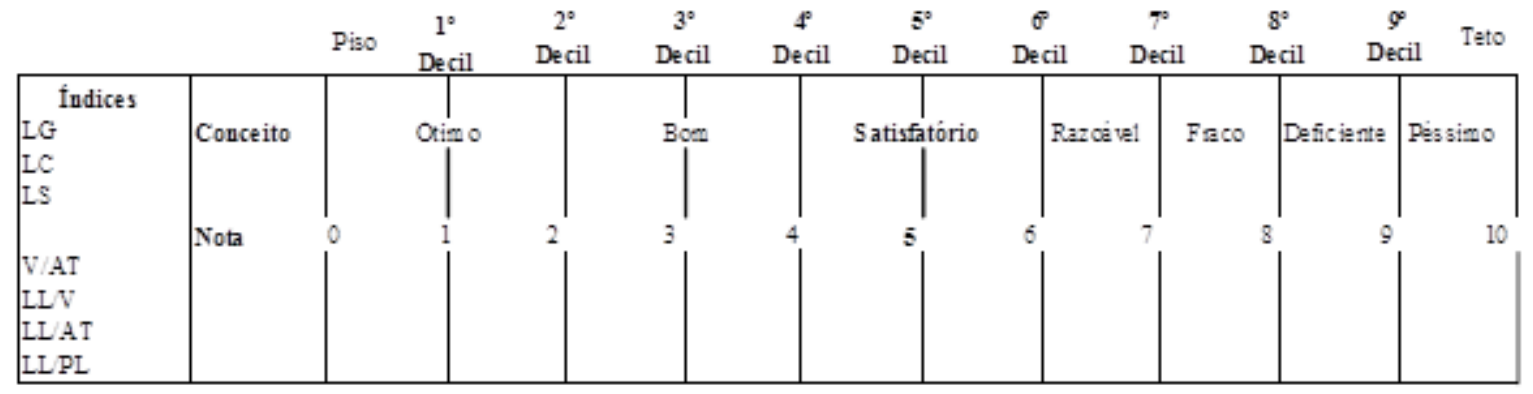

Fonte: Adaptado de Matarazzo (2003, p. 209)

A tabela 3 exibe as notas e conceitos que foram atribuidas aos índices conforme sua posição relativa. Depois de de realizada essas atribuições, pode-se realizar a avaliação de cada índice, grupo de índice ou realizar uma análise global da empresa, onde observa-se uma mair constância de notas para o Banco Daycoval e o Banco Industrial e Comercial, e notas de menor potencial para o Banco Alfa de Investimentos.

Tabela 3 Avaliação dos Índices das Instituições Financeiras Bancárias de acordo com a sua posição relativa

\begin{tabular}{|c|c|c|c|c|c|c|c|c|c|c|c|}
\hline \multirow[b]{2}{*}{ Instituições Financeiras } & \multicolumn{4}{|c|}{ Estrutura de Capitais } & \multicolumn{3}{|c|}{ Liquidez } & \multicolumn{4}{|c|}{ Rentabilidade } \\
\hline & $\mathrm{ET} / \mathrm{PL}$ & $\mathrm{PC} / \mathrm{ET}$ & ANC-RLP/PL & $\begin{array}{c}\text { ANC- } \\
\text { RLP/ } \\
\text { PL+PELP }\end{array}$ & LG & $\mathrm{LC}$ & LS & VL/AT & $\mathrm{LL} / \mathrm{VL}$ & LL/AT & $\mathrm{LL} / \mathrm{PL}$ \\
\hline ALFA HOLDINGS S.A & 10 & 0 & 1 & 0 & 10 & 10 & 10 & 0 & 10 & 10 & 2 \\
\hline BANESTES S.A. - BCO EST ESPIRITO SANTO & 1 & 2 & 5 & 5 & 4 & 1 & 1 & 4 & 7 & 4 & 9 \\
\hline BCO ABC BRASIL S.A & 6 & 1 & 10 & 10 & 8 & 3 & 3 & 4 & 8 & 5 & 4 \\
\hline BCO ALFA DE INVESTIMENTO S.A & 3 & 6 & 3 & 3 & 4 & 3 & 3 & 1 & 9 & 2 & 3 \\
\hline BCO BRADESCO S.A & 1 & 6 & 0 & 1 & 0 & 5 & 5 & 3 & 9 & 3 & 8 \\
\hline BCO CRUZEIRO DO SUL S.A & 6 & 4 & 5 & 4 & 8 & 8 & 8 & 10 & 4 & 8 & 7 \\
\hline BCO DAYCOVAL S.A & 8 & 4 & 8 & 7 & 9 & 8 & 8 & 9 & 7 & 8 & 5 \\
\hline BCO ESTADO DE SERGIPE S.A. - BANESE & 0 & 7 & 4 & 6 & 4 & 4 & 4 & 9 & 2 & 3 & 10 \\
\hline BCO ESTADO DO RIO GRANDE DO SUL S.A & 4 & 1 & 5 & 3 & 6 & 2 & 2 & 9 & 5 & 6 & 7 \\
\hline BCO INDUSTRIAL E COMERCIAL S.A & 5 & 4 & 6 & 7 & 7 & 6 & 6 & 9 & 6 & 7 & 8 \\
\hline BCO INDUSVAL S.A & 7 & 3 & 7 & 6 & 8 & 7 & 7 & 10 & 6 & 9 & 6 \\
\hline
\end{tabular}


Análise dos indicadores contábeis para estimativa de retorno de aplicações: estudo empírico realizado com as ações das instituições bancarias listadas na bolsa de valores de São Paulo

Gustavo Henrique Francisco da Costa, Laércio Juarez Melz, Josiane Silva Costa dos Santos, Ariel Lopes Torres

\begin{tabular}{|c|c|c|c|c|c|c|c|c|c|c|c|}
\hline BCO MERCANTIL DE INVESTIMENTOS S.A & 0 & 10 & 10 & 10 & 4 & 9 & 9 & 2 & 2 & 0 & 1 \\
\hline BCO MERCANTIL DO BRASIL S.A & 2 & 8 & 3 & 5 & 4 & 9 & 9 & 6 & 0 & 1 & 2 \\
\hline BCO NORDESTE DO BRASIL S.A & 3 & 9 & 7 & 8 & 6 & 8 & 8 & 5 & 8 & 7 & 9 \\
\hline BCO PANAMERICANO S.A & 9 & 7 & 6 & 4 & 9 & 4 & 4 & 10 & 1 & 9 & 6 \\
\hline BCO PINE S.A & 4 & 3 & 8 & 8 & 7 & 5 & 5 & 9 & 3 & 6 & 6 \\
\hline BCO SANTANDER (BRASIL) S.A & 8 & 6 & 2 & 1 & 2 & 2 & 2 & 3 & 5 & 2 & 0 \\
\hline BCO SOFISA S.A & 7 & 8 & 2 & 2 & 5 & 6 & 6 & 6 & 3 & 4 & 3 \\
\hline BRB BCO DE BRASILIA S.A & 2 & 2 & 0 & 2 & 1 & 0 & 0 & 6 & 4 & 5 & 10 \\
\hline CONSORCIO ALFA DE ADMINISTRACAO S.A & 9 & 0 & 1 & 0 & 10 & 10 & 10 & 0 & 10 & 10 & 4 \\
\hline
\end{tabular}

Após calcular as notas e conceitos das instiuições financeiras, foi realizado uma avialação global das empresas, para que se podesse separar as instituições "boas" das "ruins". Para tal separação foram empregadas as fórmulas de avaliação dos índices apontadas por Matrazzo (2003, p. 2010).

$$
\begin{aligned}
& N E=0,6 \frac{E T}{P L}+0,1 \frac{P C}{E T}+0,2 \frac{A N C-R L P}{P L}+0,1 \frac{A N C-R L P}{P L+P E L P} \\
& N L=0,3 L G+0,5 L C+0,2 L S \\
& N R=0,2 \frac{V L}{A T}+0,1 \frac{L L}{V L}+0,1 \frac{L L}{A T}+0,6 \frac{L L}{P L} \\
& N G E=0,4 N E+0,2 N L+0,4 N R
\end{aligned}
$$

Onde:

$\mathrm{NE}=$ nota da estrutura

$\mathrm{NL}=$ nota da liquidez

$\mathrm{NR}=$ nota da rentabilidade

NGE $=$ nota global da empresa

A figura 5 exibi os conceitos e anotas empregados para avaliação dos grupos de índices, e avaliação global da empresa.

Figura 5 Nota Global das Instituições Financeiras convertidas em conceitos

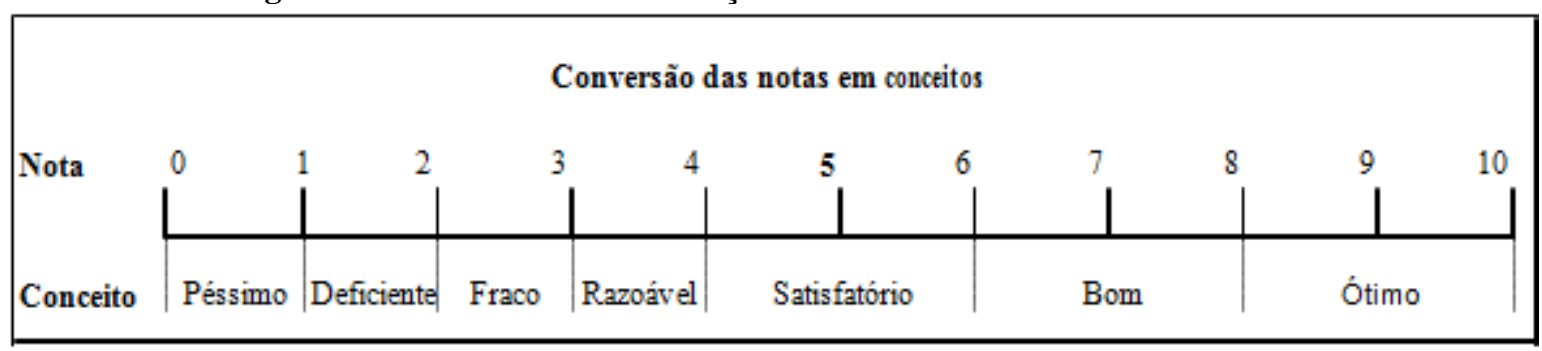

Fonte: Matarazzo (2003, p. 211) 
Análise dos indicadores contábeis para estimativa de retorno de aplicações: estudo empírico realizado com as ações das instituições bancarias listadas na bolsa de valores de São Paulo

Gustavo Henrique Francisco da Costa, Laércio Juarez Melz, Josiane Silva Costa dos Santos, Ariel Lopes Torres

Com a intenção de facilitar essa pesquisa, os cálculos efetuados para avaliação dos grupos dos índices, estrutura de capitais, liquidez e rentabilidade, foram realizados com auxilio da planilha eletrônica encontrada no Office Exel 2010 da Microsoft. A tabela 4 exibe as notas e os conceitos da avaliação global das instituições financeiras, observando que o Banco Daycoval e o Banco Industrial e comercial, são os bancos que se apresentam com melhores notas, e o Banco Alfa de Investimento se apresentou com as menores notas para o período referenciado pela tabela.

Tabela 4 Notas e conceitos das Instituições Financeiras Bancárias no de 2009.

\begin{tabular}{c|c|c|c|c|c}
\hline Instituições Financeiras & Estrutura & Liquidez & Rentabilidade & Nota Global & Conceito \\
\hline BCO DAYCOVAL S.A & 8,10 & 9,00 & 8,10 & 7,68 & Satisfatório \\
BCO INDUSTRIAL E COMERCIAL S.A & 5,60 & 6,60 & 5,60 & 6,80 & Satisfatório \\
BCO NORDESTE DO BRASIL S.A & 4,80 & 7,40 & 6,90 & 6,68 & Satisfatório \\
BCO ABC BRASIL S.A & 6,90 & 6,90 & 7,80 & 6,66 & Satisfatório \\
ALFA HOLDINGS S.A & 6,20 & 9,30 & 3,80 & 6,34 & Satisfatório \\
BCO PANAMERICANO S.A & 6,60 & 5,20 & 3,00 & 6,28 & Satisfatório \\
CONSORCIO ALFA DE ADMINISTRACAO S.A & 6,00 & 10,00 & 4,40 & 5,68 & Razoável \\
BCO CRUZEIRO DO SUL S.A & 4,90 & 8,40 & 5,90 & 5,36 & Razoável \\
BRB BCO DE BRASILIA S.A & 2,50 & 2,20 & 6,30 & 5,20 & Razoável \\
BCO INDUSVAL S.A & 6,10 & 7,60 & 0,60 & 5,00 & Razoável \\
BCO PINE S.A & 5,20 & 5,60 & 7,80 & 5,00 & Razoável \\
\hline BCO ESTADO DO RIO GRANDE DO SUL S.A & 3,80 & 3,20 & 3,80 & 4,96 & Razoável \\
BCO ESTADO DE SERGIPE S.A. - BANESE & 1,60 & 3,00 & 9,40 & 4,76 & Razoável \\
BCO BRADESCO S.A & 2,00 & 3,50 & 7,60 & 4,54 & Razoável \\
BCO MERCANTIL DE INVESTIMENTOS S.A & 4,00 & 7,30 & 4,00 & 4,50 & Razoável \\
BANESTES S.A. - BCO EST ESPIRITO SANTO & 2,00 & 2,60 & 5,80 & 4,40 & Razoável \\
BCO MERCANTIL DO BRASIL S.A & 2,40 & 6,20 & 6,40 & 3,84 & Fraco \\
BCO SANTANDER (BRASIL) S.A & 5,70 & 3,30 & 2,90 & 3,78 & Fraco \\
BCO SOFISA S.A & 4,40 & 5,70 & 2,50 & 3,42 & Fraco \\
BCO ALFA DE INVESTIMENTO S.A & 2,80 & 1,60 & 3,50 & 3,08 & Fraco \\
\hline
\end{tabular}

Após atribuídos notas e conceitos, e separados os grupos das intuições "boas" e "ruins". Com o intuito de atender o terceiro objetivo secundário desse trabalho, analisou-se a relação da notas e conceitos das intuições, com o retorno de suas respectivas ações. Para calcular o valor do retorno das ações, foi empregada a seguinte equação.

$H_{T}=\frac{G_{T}-G_{T-1}}{G_{T-1}}$

Onde:

$H_{T}=$ retorno total da ação, no ano $\mathrm{T}$;

$G_{T}=$ cotação de fechamento da ação, no ano $\mathrm{T}$, ajustada a dividendos e outros proventos ocorridos no período; 
Análise dos indicadores contábeis para estimativa de retorno de aplicações: estudo empírico realizado com as ações das instituições bancarias listadas na bolsa de valores de São Paulo

Gustavo Henrique Francisco da Costa, Laércio Juarez Melz, Josiane Silva Costa dos Santos, Ariel Lopes Torres

$G_{T-1}=$ cotação de fechamento da ação, no ano T-1.

As tabelas 5, 6, 7 e 8 exibem a relação das notas e conceitos das instituições financeiras "boas" e "ruins", com média do retorno das suas ações, sendo que essas tabelas resumem toda a pesquisa. Ficando evidente, que as empresas que possuem as melhores notas e conceitos são aquelas, que terão um maior retorno de suas ações. Como observado nas tabelas anteriores os bancos Daycoval e Industrial e Comercail, são as instituições financeiras que apresentaram os melhores notas e conceitos, verificando-se que ambos tiveram aumentos notáveis no retorno de suas ações, e o banco Alfa de Investimento, que vinha se apresentando com as piores notas e conceitos, foi um dos bancos que tiveram piores retornos dos valores de suas ações, como demonstra a tabela 6 .

Tabela 5 Análise dos retornos das ações das Instituições Financeiras versus conceitos, no ano de 2008

\begin{tabular}{|c|c|c|c|c|}
\hline EMPRESAS & NOTAS & CONEITOS & RETORNO DAS AÇÕES \% & MÉDIA \% \\
\hline BCO DAYCOVAL S.A & 7,18 & Satisfatório & $-68,91$ & \multirow{11}{*}{51,59} \\
\hline BCO INDUSVAL S.A & 6,90 & Satisfatório & $-79,54$ & \\
\hline BCO PANAMERICANO S.A & 6,82 & Satisfatório & $-72,02$ & \\
\hline BCO CRUZEIRO DO SUL S.A & 6,72 & Satisfatório & $-57,81$ & \\
\hline BCO NORDESTE DO BRASIL S.A & 6,60 & Satisfatório & 1094,03 & \\
\hline BCO INDUSTRIAL E COMERCIAL S.A & 6,54 & Satisfatório & $-73,14$ & \\
\hline CONSORCIO ALFA DE ADMINISTRACAO S.A & 6,00 & Satisfatório & $-1,12$ & \\
\hline ALFA HOLDINGS S.A & 5,76 & Razoável & 10,75 & \\
\hline BCO PINE S.A & 5,68 & Razoável & $-79,83$ & \\
\hline BCO ABC BRASIL S.A & 5,38 & Razoável & $-56,20$ & \\
\hline BCO ESTADO DO RIO GRANDE DO SUL S.A & 5,00 & Razoável & $-48,70$ & \\
\hline BCO ESTADO DE SERGIPE S.A. - BANESE & 4,96 & Razoável & $-54,14$ & \multirow{9}{*}{4,88} \\
\hline BCO SOFISA S.A & 4,86 & Razoável & $-73,53$ & \\
\hline BANESTES S.A. - BCO EST ESPIRITO SANTO & 4,22 & Razoável & 329,10 & \\
\hline BRB BCO DE BRASILIA S.A & 3,94 & Fraco & 4,11 & \\
\hline BCO BRADESCO S.A & 3,86 & Fraco & $-57,42$ & \\
\hline BCO MERCANTIL DO BRASIL S.A & 3,74 & Fraco & 7,04 & \\
\hline BCO MERCANTIL DE INVESTIMENTOS S.A & 3,58 & Fraco & $-36,36$ & \\
\hline BCO SANTANDER (BRASIL) S.A & 3,28 & Fraco & $-41,67$ & \\
\hline BCO ALFA DE INVESTIMENTO S.A & 3,22 & Fraco & $-33,22$ & \\
\hline
\end{tabular}

Tabela 6 Análise dos retornos das ações das Instituições Financeiras versus conceitos, no ano de 2009

\begin{tabular}{l|c|l|c|c}
\hline \multicolumn{1}{c|}{ EMPRESAS } & NOTAS & CONCEITOS & RETORNO DAS AÇÕES \% & MÉDIA \% \\
\hline BCO DAYCOVAL S.A & 7,68 & Satisfatório & 84,53 & \\
BCO INDUSTRIAL E COMERCIAL S.A & 6,80 & Satisfatório & 316,10 & 133,07 \\
BCO NORDESTE DO BRASIL S.A & 6,68 & Satisfatório & $-7,48$ & \\
BCO ABC BRASIL S.A & 6,66 & Satisfatório & 127,36 & \\
ALFA HOLDINGS S.A & 6,34 & Satisfatório & $-6,80$ & \\
\hline
\end{tabular}


Análise dos indicadores contábeis para estimativa de retorno de aplicações: estudo empírico realizado com as ações das instituições bancarias listadas na bolsa de valores de São Paulo

Gustavo Henrique Francisco da Costa, Laércio Juarez Melz, Josiane Silva Costa dos Santos, Ariel Lopes Torres

\begin{tabular}{l|l|l|l|} 
BCO PANAMERICANO S.A & 6,28 & Satisfatório & 323,69 \\
CONSORCIO ALFA DE ADMINISTRACAO S.A & 5,68 & Razoável & $-2,05$ \\
BCO CRUZEIRO DO SUL S.A & 5,36 & Razoável & 154,40 \\
BRB BCO DE BRASILIA S.A & 5,20 & Razoável & 166,81 \\
BCO INDUSVAL S.A & 5,00 & Razoável & 107,77 \\
BCO PINE S.A & 5,00 & Razoável & 199,44 \\
\hline BCO ESTADO DO RIO GRANDE DO SUL S.A & 4,96 & Razoável & 126,44 \\
BCO ESTADO DE SERGIPE S.A. - BANESE & 4,76 & Razoável & 98,68 \\
BCO BRADESCO S.A & 4,54 & Razoável & 61,04 \\
BCO MERCANTIL DE INVESTIMENTOS S.A & 4,50 & Razoável & 22,86 \\
BANESTES S.A. - BCO EST ESPIRITO SANTO & 4,40 & Razoável & 20,87 \\
BCO MERCANTIL DO BRASIL S.A & 3,84 & Fraco & 37,37 \\
BCO SANTANDER (BRASIL) S.A & 3,78 & Fraco & 57,14 \\
BCO SOFISA S.A & 3,42 & Fraco & 48,33 \\
BCO ALFA DE INVESTIMENTO S.A & 3,08 & Fraco & 19,97 \\
\hline
\end{tabular}

Tabela 7 Análise dos retornos das ações das Instituições Financeiras versus conceitos, no ano de 2010

\begin{tabular}{|c|c|c|c|c|}
\hline EMPRESAS & NOTAS & CONEITOS & RETORNO DAS AÇÕES \% & MÉDIA \% \\
\hline BCO DAYCOVAL S.A & 7,58 & Satisfatório & 32,41 & \multirow{14}{*}{24,72} \\
\hline BCO ABC BRASIL S.A & 6,54 & Satisfatório & 23,90 & \\
\hline BCO INDUSTRIAL E COMERCIAL S.A & 6,52 & Satisfatório & 16,46 & \\
\hline BCO CRUZEIRO DO SUL S.A & 6,38 & Satisfatório & 19,50 & \\
\hline ALFA HOLDINGS S.A & 6,00 & Satisfatório & 7,71 & \\
\hline CONSORCIO ALFA DE ADMINISTRACAO S.A & 6,00 & Satisfatório & 35,73 & \\
\hline BCO ESTADO DO RIO GRANDE DO SUL S.A & 5,78 & Razoável & 33,98 & \\
\hline BRB BCO DE BRASILIA S.A & 5,68 & Razoável & 32,00 & \\
\hline BCO SOFISA S.A & 5,68 & Razoável & $-4,87$ & \\
\hline BCO NORDESTE DO BRASIL S.A & 5,64 & Razoável & 57,93 & \\
\hline BCO ESTADO DE SERGIPE S.A. - BANESE & 5,44 & Razoável & 39,95 & \\
\hline BCO MERCANTIL DO BRASIL S.A & 5,42 & Razoável & 15,90 & \\
\hline BCO INDUSVAL S.A & 5,12 & Razoável & $-4,10$ & \\
\hline BCO PINE S.A & 5,12 & Razoável & 39,53 & \\
\hline BANESTES S.A. - BCO EST ESPIRITO SANTO & 4,82 & Razoável & $-12,23$ & \multirow{6}{*}{$-18,24$} \\
\hline BCO BRADESCO S.A & 4,38 & Razoável & $-10,25$ & \\
\hline BCO ALFA DE INVESTIMENTO S.A & 4,18 & Razoável & $-7,07$ & \\
\hline BCO SANTANDER (BRASIL) S.A & 3,98 & Fraco & $-13,64$ & \\
\hline BCO MERCANTIL DE INVESTIMENTOS S.A & 2,32 & Deficiente & $-4,65$ & \\
\hline BCO PANAMERICANO S.A & 1,22 & Deficiente & $-61,61$ & \\
\hline
\end{tabular}

\begin{tabular}{l|c|l|c|c}
\hline \multicolumn{1}{c}{ Tabela 8 Análise dos retornos das ações das Instituições Financeiras versus conceitos, no ano de 2011 } \\
\hline \multicolumn{1}{c|}{ EMPRESAS } & NOTAS & CONEITOS & RETORNO DAS AÇÕES & MÉDIA \\
\hline BCO DAYCOVAL S.A & 7,74 & Satisfatório & $-27,41$ & \\
BCO ABC BRASIL S.A & 7,04 & Satisfatório & $-14,71$ & $-9,70$ \\
BCO ESTADO DO RIO GRANDE DO SUL S.A & 6,52 & Satisfatório & 3,35 & \\
BCO PINE S.A & 6,26 & Satisfatório & $-11,67$ & \\
\end{tabular}


Análise dos indicadores contábeis para estimativa de retorno de aplicações: estudo empírico realizado com as ações das instituições bancarias listadas na bolsa de valores de São Paulo

Gustavo Henrique Francisco da Costa, Laércio Juarez Melz, Josiane Silva Costa dos Santos, Ariel Lopes Torres

\begin{tabular}{l|l|l|l|l} 
BCO CRUZEIRO DO SUL S.A & 6,08 & Satisfatório & $-9,54$ & \\
BCO INDUSTRIAL E COMERCIAL S.A & 6,06 & Satisfatório & $-46,64$ & $-7,18$ \\
CONSORCIO ALFA DE ADMINISTRACAO S.A & 5,96 & Razoável & 68,02 & \\
BCO ESTADO DE SERGIPE S.A. - BANESE & 5,40 & Razoável & $-34,99$ & \\
BCO NORDESTE DO BRASIL S.A & 5,40 & Razoável & $-7,32$ & \\
BCO MERCANTIL DE INVESTIMENTOS S.A & 5,22 & Razoável & $-4,06$ & \\
ALFA HOLDINGS S.A & 5,16 & Razoável & $-24,21$ & \\
BCO SOFISA S.A & 5,10 & Razoável & $-3,31$ & $-1,67$ \\
\hline BCO MERCANTIL DO BRASIL S.A & 4,64 & Razoável & $-5,82$ & \\
BCO BRADESCO S.A & 4,40 & Razoável & $-18,79$ & \\
BRB BCO DE BRASILIA S.A & 4,14 & Razoável & 49,38 & \\
BCO PANAMERICANO S.A & 3,88 & Fraco & $-15,09$ & \\
BCO INDUSVAL S.A & 3,80 & Fraco & $-26,32$ \\
BCO SANTANDER (BRASIL) S.A & 3,62 & Fraco & 23,77 & $-17,16$ \\
BANESTES S.A. - BCO EST ESPIRITO SANTO & 3,50 & Fraco & \\
BCO ALFA DE INVESTIMENTO S.A & 3,30 & Fraco & \\
\hline
\end{tabular}

\section{CONCLUSÃO}

O propósito desta pesquisa foi identificar, através de testes quantitativos, qualitativos e ferramentas estatísticas, a relevância dos indicadores contábeis no mercado de capitais. Para isso este estudo teve como base, o modelo de avaliação de empresas apresentado por Matarazzo (2010). Este modelo foi empregado com o intuito de selecionar as instituições financeiras com melhor potencial de investimento, visando auxiliar o investidor na sua tomada de decisões.

Os resultados dos testes empíricos, para três anos (2008, 2009 e 2010) dos quatro analisados, na avaliação geral das empresas são relevantes, como demonstra as tabelas 5, 6 e 7. As empresas que se presentaram com os melhores índices foram as que tiverem um maior retorno de suas ações. Demonstrando dessa forma que as informações interpretadas como boas ou ruins, contidas nas demonstrações contábeis que são divulgadas refletirão nos preços das ações.

Porém, em 2011 os resultados nos levam pra rejeição da hipótese desta pesquisa, como apresentado pela tabela 8. Vários são os motivos que podem ter contribuído para que isto ocorresse. Primeiramente, o fato do mundo estar em crise econômica iniciada com o estouro da "bolha imobiliária" nos Estados Unidos no ano de 2008, que devido a globalização se dispersou pelo mundo atingindo a Europa, podendo ter atingindo o Brasil no ano de 2011 com maior intensidade. Outro motivo pode ter sido a descoberta de uma fraude nas 
Análise dos indicadores contábeis para estimativa de retorno de aplicações: estudo empírico realizado com as ações das instituições bancarias listadas na bolsa de valores de São Paulo

Gustavo Henrique Francisco da Costa, Laércio Juarez Melz, Josiane Silva Costa dos Santos, Ariel Lopes Torres

Demonstrações Contábeis de uma das Instituições financeiras no ano de 2010, que quase a levou abrir falência, fazendo com que os investidores criassem um descrédito para com o restante das instituições financeiras no ano seguinte, tal descrédito pode ser observardo na tabela 8, em que ambos os grupos de empresas, "boas" e "ruins", tiveram a média de seus retornos negativos, demonstrando a queda de interesses dos investidores pra com as ações das instituições financeiras bancárias.

Segundo Hendrikesen e Brenda (1999, p. 206) os preços das ações são formados por uma soma de vários fatores mais abrangente do que aqueles representados nas informações contábeis, "os preços reagem a coisas tão exóticas como boatos de guerra e tão corriqueiros quanto variação da taxa de juros de letra do tesouro".

Sugere-se para pesquisas futuras a elaboração de pesos específicos voltados para as instituições financeiras, com o intuito de encontrar evidências mais significativas. 
Análise dos indicadores contábeis para estimativa de retorno de aplicações: estudo empírico realizado com as ações das instituições bancarias listadas na bolsa de valores de São Paulo

Gustavo Henrique Francisco da Costa, Laércio Juarez Melz, Josiane Silva Costa dos Santos, Ariel Lopes Torres

\section{REFERÊNCIAS}

ANDREZO, Andrea Fernandes, LIMA, Iran Siqueira. Mercado Financeiro: aspectos históricos e conceituais. 2 Ed - São Paulo: Pioneira Thomson Laerning, 2002.

BCB, Banco Central do Brasil, Bancos Comerciais, 2012, Disponível em <http://www.bcb.gov.br/pre/composicao/bc.asp> Acesso em 17 Mar. 2012.

BCB, Banco Central do Brasil, Bancos de Desenvolvimento, 2012, Disponível em <http://www.bcb.gov.br/pre/composicao/bd.asp> Acesso em 17 Mar. 2012.

BCB, Banco Central do Brasil, Bancos de Investimento, 2012, Disponível em <http://www.bcb.gov.br/pre/composicao/bi.asp> Acesso em 17 Mar. 2012.

BCB, Banco Central do Brasil, Bancos Múltiplos, 2012, Disponível em <http://www.bcb.gov.br/pre/composicao/bm.asp> Acesso em 17 Mar. 2012.

BRUNI, Adriano Leal. Mercados financeiros: Para certificação profissional ANBID 10 (CPA-10) - São Paulo: Atlas, 2005.

CVM, Comissão de Valores Mobiliários, Cadernos CVM: Mercado de Balcão Organizado, Caderno. São Paulo, 2012..

FORTUNA, Eduardo. Mercado Financeiro: produtos e serviços. 16 Ed - Rio de Janeiro: Qualitymark 2005.

MARION, José Carlos. Análise das demonstrações contábeis: contabilidade empresarial. 3. Ed. - reimpr. - São Paulo: Atlas, 2007.

MARION, José Carlos. Contabilidade básica 8. Ed. - 2 reimpr. - São Paulo: Atlas, 2007. MATARAZZO, Dante Carmine. Análise financeira de balanços: abordagem básica e gerencial. 6 Ed. -6 reimpr. - São Paulo: Atlas, 2007.

MELLAGI, Armando Filho, ISHIKAWA Sérigo. Mercado financeiro e de capitais. 2. Ed. São Paulo: Atlas, 2003

NEWLANDS JUNIOR, Carlos Arthur. Sistema Financeiro e bancário: teoria e questões. 2 Ed. - Rio de Janeiro: Elsevier 2010.

OLIVEIRA, Silvio Luiz de. Tratado de Metodologia Científica: projetos de pesquisas, TGI, TCC, monografias, dissertações e teses. 7 Ed. São Paulo: Pioneira Thomson Learning, 2002 .

RANGEL, Luciene Laurett, A Relevância dos indicadores contábeis para estimativa de retorno das ações negociadas na BOVESPA: um estudo empírico no setor de metalurgia 
Análise dos indicadores contábeis para estimativa de retorno de aplicações: estudo empírico realizado com as ações das instituições bancarias listadas na bolsa de valores de São Paulo

Gustavo Henrique Francisco da Costa, Laércio Juarez Melz, Josiane Silva Costa dos Santos, Ariel Lopes Torres

e siderurgia, 2004. Originalmente apresentada como dissertação de Pós-Graduação,

Fundação Instituto Capixaba de Pesquisas em Contabilidade, Economia e Finanças, 2004.

RIBEIRO, Osni Moura. Estrutura e Análise de Balanços fácil. 6. Ed. - São Paulo: Saraiva, 2002.

RIBEIRO, Osni Moura. Estrutura e análise de balanço fácil. 8 Ed. ampl. E atual. - São Paulo: Saraiva, 2009.

SANTOS, Milton. O Brasil: Território e Sociedade no Inicio do Século XXI. São Paulo: Record, 2011.

SEVERINO, Antônio Joaquim. Metodologia do trabalho cientifico. 23. Ed. Ver. E atualizada - São Paulo: Cortez, 2007.

SILVA, Ermes Medeiros, Iet al. Estatística para os cursos de: Economia, Administração, Ciências Contábeis. 3. Ed. 9. Reimpr. - São Paulo: Atlas, 2006.

HENDRIKSEN, Eldon S., BREDA, Michael F. Van. Teoria da contabilidade. São

Paulo: Atlas, 1999. 